\title{
Awareness of Cyclic Loading Testing Machine Among Undergraduate Students - A Cross Sectional Survey
}

\author{
K. Thirumagal ${ }^{1}$, Revathi Duraisamy ${ }^{2}$ and Dhanraj Ganapathy ${ }^{3}$ \\ ${ }^{1}$ Saveetha Dental College \&t Hospital Saveetha Institute of Medical and Technical Sciences, Hospital \\ Saveetha University 162, Poonamallee High Road Chennai - 600077, India \\ ${ }^{2}$ Senior Lecturer Department of Prosthodontics Saveetha Dental College \& Hospital Saveetha Institute of Medical \\ and Technical Sciences, Saveetha University 162, Poonamallee High Road Chennai - 600077, India \\ Senior Lecturer Department of Prosthodontics Saveetha Dental College \& Hospital Saveetha Institute of Medical \\ and Technical Sciences, Saveetha University 162, Poonamallee High Road Chennai - 600077, India
}

\section{ABSTRACT}

Cyclic loading testing machine is important to test the strength of core build up material under cyclic loading. The presence of tensile stress in specimens after the load has been loaded . It has been stated that under repeated load the tensile stresses vary in a cyclic manner that may result in fatigue cracks in subsurface areas. The aim of the study was to find awareness of cyclic loading testing machines among undergraduate (UG) students of a Dental College. The survey was conducted among 100 undergraduate students of Dental College and Hospital. A questionnaire consisting of 11 questions regarding cyclic loading testing machines was framed and shared using a link created by google forms to UG students of Dental College. Then the data were collected, results were finally tabulated and imported using SPSS. The results showed that 3rd year (25.0\%), 4th year (10.7\%), Intern (9.8\%) of them had higher awareness about cyclic loading testing machines than 1st year and 2nd year undergraduate dental students. Association was done between the year of the study participants and the knowledge and awareness on cyclic loading testing machines, it was found to be statistically significant since $p$ value $<0.05$. Within the limitations of the study, we can conclude that 3 rd year $(25.0 \%)$, 4th year (10.7\%) and Interns (9.8\%) had higher awareness about cyclic loading testing machines than 1st year and 2nd year undergraduate dental students. Therefore for the 1st and 2nd year undergraduate dental students group discussion and seminar can be conducted in order to create awareness on cyclic loading testing machines.

KEY WORDS: CYCLIC LOADING; TESTING MACHINE; COMPRESSIVE STRESS; LOAD; STRENGTH..

\section{INTRODUCTION}

The Tensile compression cyclic loading is a complex behavior deformation under cyclic loading. In the tensile

\section{ARTICLE INFORMATION}

*Corresponding Author: revathid.sdc@saveetha.com Received 15th June 2020 Accepted after revision 5th August 2020 Print ISSN: 0974-6455 Online ISSN: 2321-4007 CODEN: BBRCBA

Thomson Reuters ISI Web of Science Clarivate Analytics USA and Crossref Indexed Journal

\section{Clarivate
Analytics}

NAAS Journal Score 2020 (4.31) SJIF: 2020 (7.728)

A Society of Science and Nature Publication,

Bhopal India 2020. All rights reserved.

Online Contents Available at: http//www.bbrc.in/

Doi: $h t t p: / / d x$.doi.org/10.21786/bbrc/13.7/77 compression cyclic loading process most of the metal will tend to appear in the Bauschinger Effect [1]. The curve of stress-strain under the cyclic loading can be directly obtained by tensile-compression cyclic loading test [2]. All-ceramic dental restorations is widely applied in the prosthodontics due to the properties like aesthetic,inert properties and biocompatible [3]. The Dynamic fatigue testing will provide an efficient means for estimating the materials long-term mechanical properties under a constant ratio of cyclic stress. Mechanical degradation in toughness and flexural stress has been realized in different dental ceramics [4], [5]. 
The dental ceramics that has flaws and defects in it can act as a localized stress concentrators, even-though the stress which has been created by less mastication loads that doesn't even exceed their characteristic strength, these type of stresses can lead to subcritical crack growth, which may finally lead to substantial reduction in strength and failure in catastrophic potential [6], [7]. The definition for the fracture toughness is the critical stress intensity factor at which a given flaw starts growing, and it indicates the intrinsic capacity of a material to resist rapid crack propagation and consequent catastrophic failure [8]. The significant increase in flexible strength is shown in CAD/CAM ceramic but it doesn't satisfy the strength of fracture resistance after cyclic loading. Fatigue is responsible for all mechanical failures which is estimated to be 90\% [9]. The load bearing capacities of all-ceramic crowns would reduce after combined with cyclic stress and moist and thermal cycling [10],[11].

Newly, the quasi-static fracture tests have shown that the ageing of the cement is due to moisture that can also lead to decrease in load-bearing capacities of crowns made of all-ceramic [12]. Reference of various literature compared the type of cement retentiveness used in implant dentistry along with the different types of restorations in prosthetic, abutments and different conditions in compressive loading, and different simulating intraoral conditions [13], [14]. In contrast, there are very few references that compares the retentiveness before and after the cyclic compressive loading which will be similar to mastication and this will decide whether the final retention of these various types of cement after a long duration of mastication is sufficient to support the retrievability and simultaneous the presence of restoration in the place [15]. There are studies reported that the various materials will exhibit different types of responses while subjected to cyclic loading some materials tend to become more stronger and ductile, whereas others tend to become weaker and more brittle [16].

Previously our department has published extensive research on various aspects of prosthetic dentistry [17-27], this vast research experience has inspired us to research about awareness of cyclic loading testing machine among undergraduate students of a Dental College

\section{MATERIAL AND METHODS}

This was a cross sectional questionnaire based study, which was done in the month of December 2019 among Undergraduate students of Saveetha Dental College. The present study was an online based survey. The participants were from 1st, 2nd, 3rd, 4th and Intern year of BDS. The study was approved by the Institutional Review Board. The predesigned validated questionnaire was used to analyse the awareness of cyclic loading testing machines among undergraduate students of a dental college. Validated and structured questionnaires containing 11 questions were framed and it was distributed among dental students through an online link from google form. It consists of two parts: section I demographic data of the participants which includes students' year of study were obtained from the responses and further analysis. and section II awareness of cyclic loading testing machines.

The sample size was 100 undergraduate dental students and the sampling method used was a simple random sampling method and only the completed surveys were included for analysis. In order to minimise bias all variables were included (Randomisation) and no sorting process was done. Participants in this study were voluntary. Independent variables were demographics such as year of the study of participants. Dependent variables were types of cyclic loading testing machine, function, principles. Data collected was verified by 2 reviewers. Internal validity was a pretested questionnaire and external validity was Homogenisation, replication of experiment and cross verification with existing studies.

The Data analysis was done using Statistical Product and Service Solutions (SPSS) software 20.0 and the statistics used for analysis was Descriptive statistics and comparison of variables were done using chi square test where $p<0.05$, statistically significant. Type of analysis used was association and the results were tabulated in excel sheet and transferred to SPSS software to analyse and represented in the bar graph.

\section{RESULTS AND DISCUSSION}

The study sample contains 100 undergraduate students of a dental college, from 1st, 2nd, 3rd, 4th and Intern. In that majority of them participated from 3rd year (42.0\%). Previous studies done regarding awareness of cyclic loading testing machines among dental students were sparse. And studies regarding the testing of various materials on cyclic loading testing machines were available.

The 3rd year students are more aware of cyclic loading testing machines followed by 4th year and Interns (Figure 1). Patterson et al. [28] in their study they tested cyclic loading on 4 mesh. And successful analysis was done using the DIC(Digital Image correlation) testing was only achieved for the two meshes Mersilene and Marlex showed the lowest levels of modulus that changed during the 200 cycles. Whereas Gynemesh and Bard Soft deformation was too large.

The 3rd year (22.09\%), followed by Interns (12.79\%) and 4 th year (10.47\%) know that application of cyclic loads to metal or alloys in aggressive environments often result in reduction of normal expected fatigue lives (Figure 2). And Guo Y et al. [29] in their study discovered two modes of failure through analysing the fracture morphology, the curves of stress-strain under the uniaxial compressive and cyclic loading, the maximum stress effect and the characteristics of fatigue damage evolution. Overall the results showed the effect of cyclic loading is clear. 
Figure 1: Bar graph shows the association between the year of the study of the participants and awareness about cyclic loading testing machines. $\mathrm{X}$ axis represents the year of the study of participants and $\mathrm{Y}$ axis represents the percentage of undergraduate students aware about cyclic loading testing machines. Chi-square test was done and association was found to be statistically significant. Pearson's Chi-square value:35.242, DF:4, p value: $0.000(<0.05)$ hence statistically significant, proving that 3rd year undergraduate students have better awareness than other years of undergraduate students.

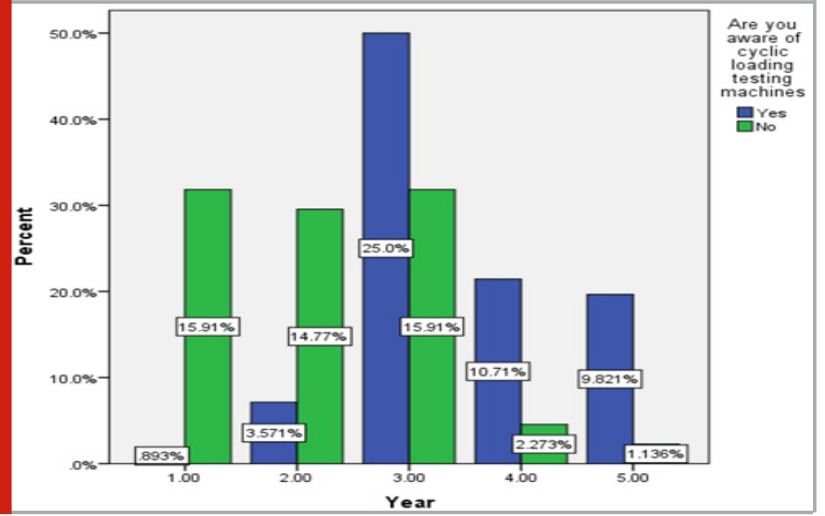

Figure 2: Bar graph shows the association between years of the study of the participants and awareness about cyclic loading testing machines. $\mathrm{X}$ axis represents the year of the study of participants and $Y$ axis represents the percentage of undergraduate students who know that application of cyclic loads to metal or alloys in aggressive environments often result in reduction of normal expected fatigue lives. Chi-square test was done and association was found to be statistically significant. Pearson's Chi-square value:26.807, DF:4, p value: $0.000(<0.05)$ hence statistically significant, proving that 3rd year (22.09\%), followed by Interns $(12.79 \%)$ and 4 th year $(10.47 \%)$ undergraduate students have better knowledge compared to 1 st and 2 nd year of undergraduate students.

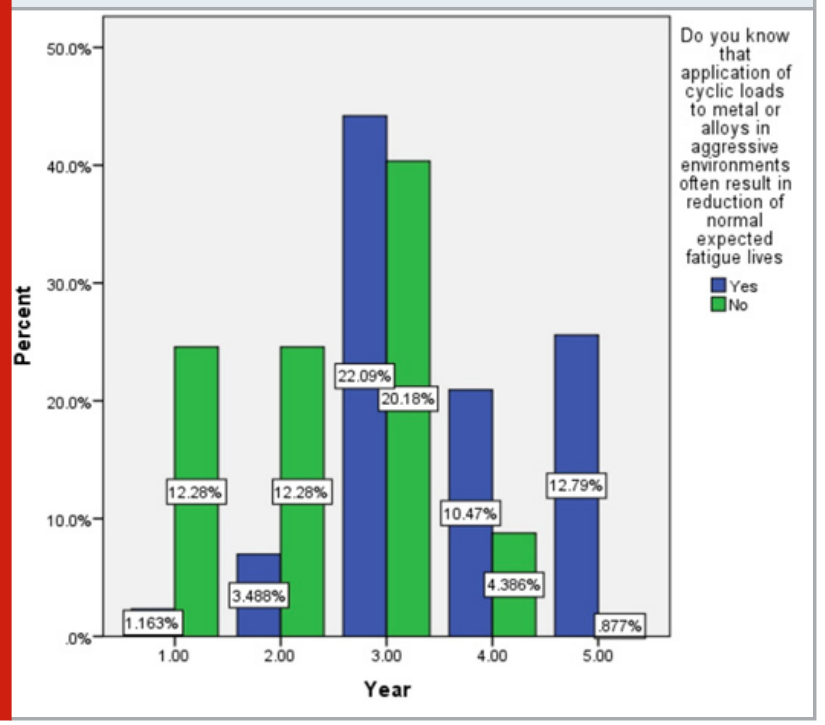

Majority of 3rd year (24.55\%), followed by 4 th year and Intern (10.0\%) were aware that axial dynamic cyclic loading testing machines are used to test endurance and life of materials and product design (Figure 3). McAlorum et al. [30] in their study they calculated the model value of $\approx 70 \mathrm{MPa}$ at that point. This was below the estimated endurance limit of the steel, $\sigma e=125 \mathrm{MPa}$. And there is possible to decrease the stress at that contact point by introducing a soft material such as rubber.

Figure 3: Bar graph shows the association between years of the study of the participants and awareness about cyclic loading testing machines. $\mathrm{X}$ axis represents the year of the study of participants and $\mathrm{Y}$ axis represents the percentage of undergraduate students who are aware that axial dynamic cyclic load testing machines are used to test the endurance and life of materials and product design. Chi-square test was done and association was found to be statistically significant. Pearson's Chi-square value:32.125, DF:4, p value: $0.000(<0.05)$ hence statistically significant, proving that 3 rd year $(24.55 \%)$, followed by 4 th year $(10.0 \%)$ and Interns (10.0\%) undergraduate students have better awareness than 1st and 2nd year of undergraduate students.

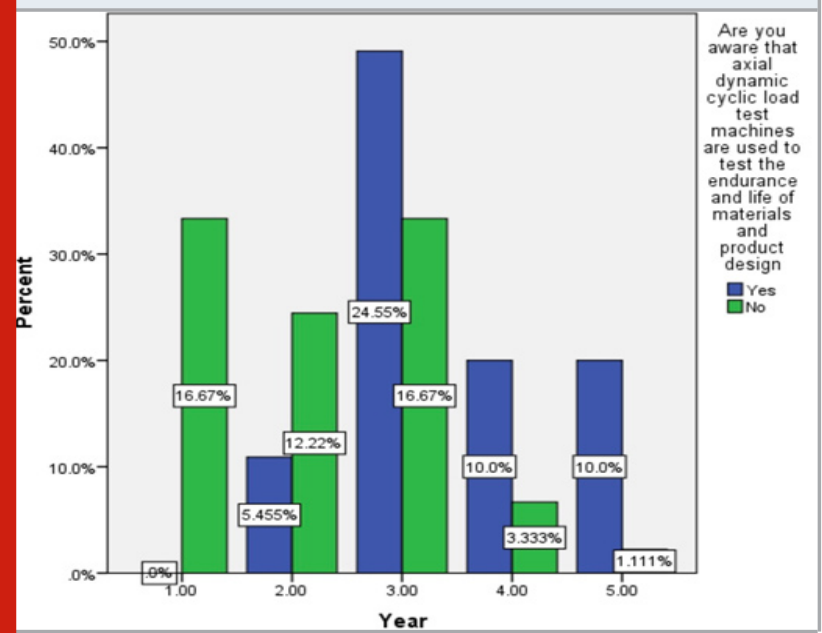

The 3rd year (16.0\%) of them choose a simple cyclic loading testing machine that is used most commonly followed by (13.1\%) axial dynamic cyclic loading testing machine (Figure 4). Liu et al. [31] in there study stated that on beginning of initial axial cyclic loading, the samples was elastic, and when the number of cycles increased, the samples changed from elastic to elastic plastic and the sample attained irreversible deformation that includes axial, volumetric and lateral strains and the magnitudes increased.

Most 3rd year (24.17\%) undergraduate students are aware that cyclic loading testing machines are used in various departments like endodontic,prosthodontics (Figure 5). Wang et al. [32] in their experimental study approach in order to evaluate the effects of fatigue loading on the fracture toughness and load-bearing capacities of various materials like IPSe.max Press and zirconia dental ceramics. The different mechanical properties after the 
cyclic loading was observed in the two types of dental specimens. And found that there was no significant influence by fatigue loading on the material properties (E,H) or KIC for zirconia. But they observed lithium disilicate core degradation due to anisotropic behaviour mechanical

Figure 4: Bar graph shows the association between years of the study of the participants and awareness about cyclic loading testing machines. $\mathrm{X}$ axis represents the year of the study of participants and $\mathrm{Y}$ axis represents the percentage of the type of cyclic loading testing machine used the most. Chi-square test was done and association was found to be statistically not significant. Pearson's Chisquare value: $15.082, \mathrm{DF}: 8, \mathrm{p}$ value: $0.058(<0.05)$ hence statistically not significant.

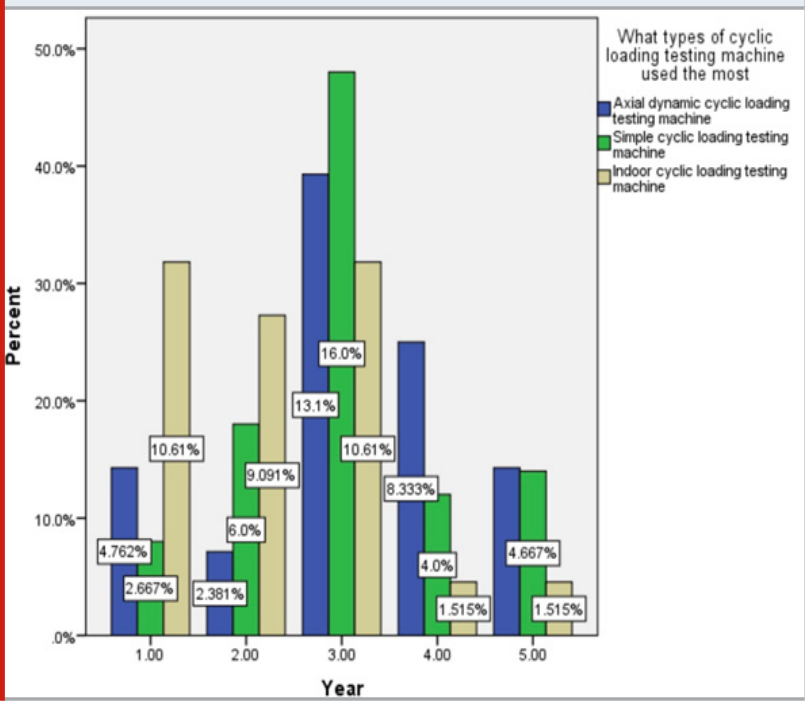

Majority of the 3rd year (25.44\%) undergraduate students agreed that cyclic compressive load decreases the retentive strength of cement (Figure 6). Alvarez et al. [33] in their study found that the cyclic compressive load decreases the retention strength of the various cement types like resin composite and resin modified glass ionomer cement types recorded the least percentage of retention loss whereas resin urethane based cement the highest.

The (24.17\%) 3rd year undergraduate students agreed that functional load applied on the anterior portion of the prosthesis can change the fit between prosthetic superstructure and implant supported abutment (Figure 7). Hecker et.al [34] in their study about the fit between the prosthetic superstructure and the implant-supported abutment gets altered when the functional loading applied on the anterior portion of the prosthesis.

Majority of them (22.39\%) 3rd years agreed that cyclic loading testing machines play an important role in dentistry (Figure 8). Choi et al. [35] in there study found a significant difference in fracture resistance between the lithium disilicate pressed on zirconia (4943.87 \pm $1243.70 \mathrm{~N})$ and monolithic lithium disilicate (2872.61 $\pm 658.78 \mathrm{~N})$ groups. And also between the groups of monolithic lithium disilicate and monolithic zirconia $(4948.02 \pm 974.51 \mathrm{~N})(\mathrm{P}<.05)$. There was no significant difference between lithium disilicate pressed on zirconia and monolithic zirconia groups found $(\mathrm{P}>$.05). In relation to fracture pattern, there were three cases of veneer chipping and two interfacial fractures in lithium disilicate pressed on zirconia group, and in all the specimens of monolithic lithium disilicate and monolithic zirconia groups complete fracture was found.

Figure 5: Bar graph shows the association between years of the study of the participants and awareness about cyclic loading testing machines. $\mathrm{X}$ axis represents the year of the study of participants and $\mathrm{Y}$ axis represents the percentage of undergraduate students who are aware that cyclic loading testing machines are used in various departments like endodontics, prosthodontics. Chi-square test was done and association was found to be statistically significant. Pearson's Chi-square value:14.371, DF:4, p value: $0.006(<0.05)$ hence statistically significant, proving that $3 \mathrm{rd}$ year $(24.17 \%)$, followed by 4 th year $(8.333 \%)$ and Intern (8.333\%) undergraduate students have better awareness compared to 1 st and 2 nd year of undergraduate students.

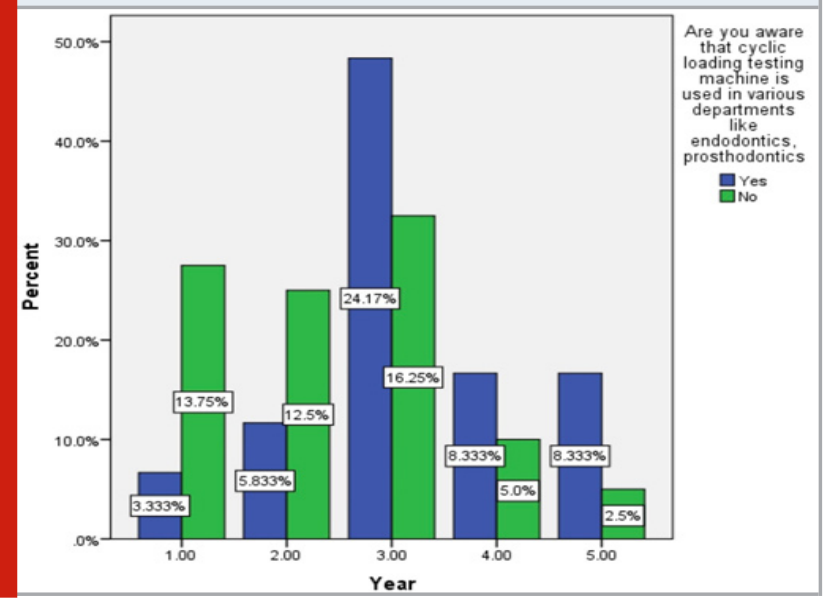

Majority (25.0\%) was aware of cyclic loading testing machine principle whereas (18.55\%) was not aware of cyclic loading testing machine principle (Figure 9). Whereas in the Mayer et al. [36] study stated about the ultrasonic equipment working principle. The measure of displacement amplitude at one end of the specimen is proportional to the strain amplitude in the centre. Hence that can be used for test generator control purposes.

Majority of 3rd year (26.6\%) are aware that Servohydraulic testing machines are available in various sizes for testing both small and large loads (Figure 10). Lieb et al. [37] in there study stated that the servo-hydraulic actuators based around a universal testing machine will provide a flexible, low-cost of biaxial testing facility and it can also be used to examine the direct influence of biaxial stress on deformation and propagation of crack, specifically in high cycle fatigue. And Lee et al.[38] in their study they demonstrated the design of a structural fatigue testing machine capable of both bending and 
torsional loading. In that a hydraulic system was incorporated in order to apply loading and to fix the test specimen.

Figure 6: Bar graph shows the association between years of the study of the participants and awareness about cyclic loading testing machines. $\mathrm{X}$ axis represents the year of the study of participants and $\mathrm{Y}$ axis represents the percentage of undergraduate students who are aware that cyclic loading testing machines are used in various departments like endodontics, prosthodontics. Chi-square test was done and association was found to be statistically significant. Pearson's Chi-square value:14.371, DF:4, p value: $0.006(<0.05)$ hence statistically significant, proving that 3rd year $(24.17 \%)$, followed by 4 th year $(8.333 \%)$ and Intern (8.333\%) undergraduate students have better awareness compared to 1 st and 2 nd year of undergraduate students.

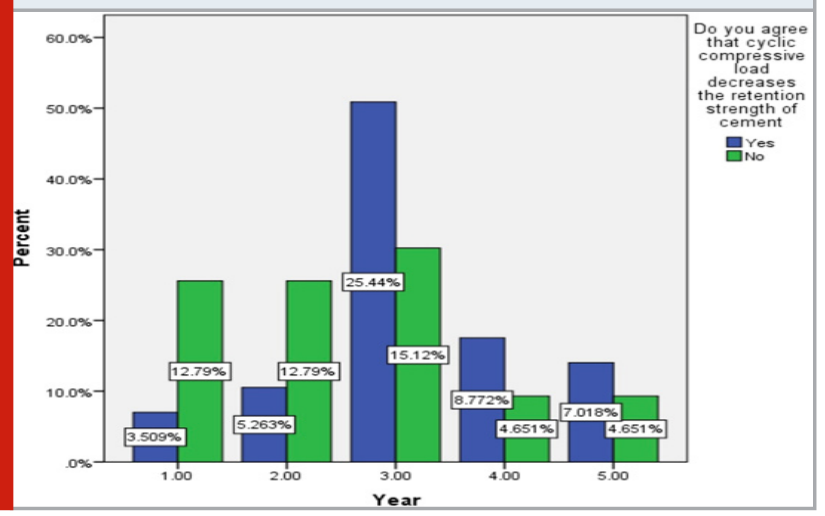

Figure 7: Bar graph shows the association between years of the study of the participants and awareness about cyclic loading testing machines. $\mathrm{X}$ axis represents the year of the study of participants and $\mathrm{Y}$ axis represents the percentage of undergraduate students that agree functional load applied on to anterior portion of the prosthesis can change the fit between prosthetic superstructure and implant supported abutment. Chisquare test was done and association was found to be statistically significant. Pearson's Chi-square value:22.782, DF:4, p value: $0.000(<0.05)$ hence statistically significant, proving that 3 rd year $(24.17 \%)$, followed by 4 th year $(9.167 \%)$ and Intern $(9.167 \%)$ undergraduate students have better awareness compared to $1 \mathrm{st}$ and 2nd year of undergraduate students.

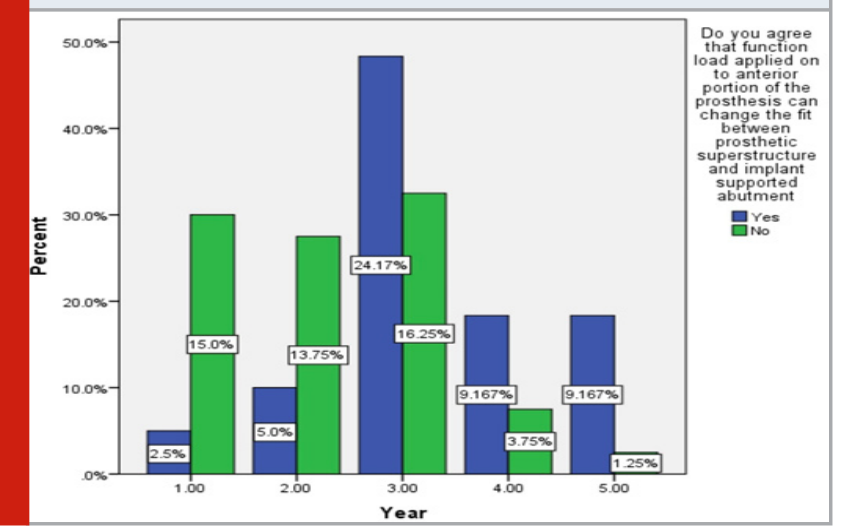

Figure 8: Bar graph shows the association between years of the study of the participants and awareness about cyclic loading testing machines. $\mathrm{X}$ axis represents the year of the study of participants and $\mathrm{Y}$ axis represents the percentage of undergraduate students that agree that cyclic loading testing machines plays an important role in dentistry. Chi-square test was done and association was found to be statistically significant. Pearson's Chi-square value:9.259, DF:4, p value: $0.055(<0.05)$ hence statistically significant, proving that 3rd year (22.39\%), followed by Intern (8.209\%) and 4th year undergraduate students have better knowledge compared to 1 st and 2 nd year of undergraduate students.

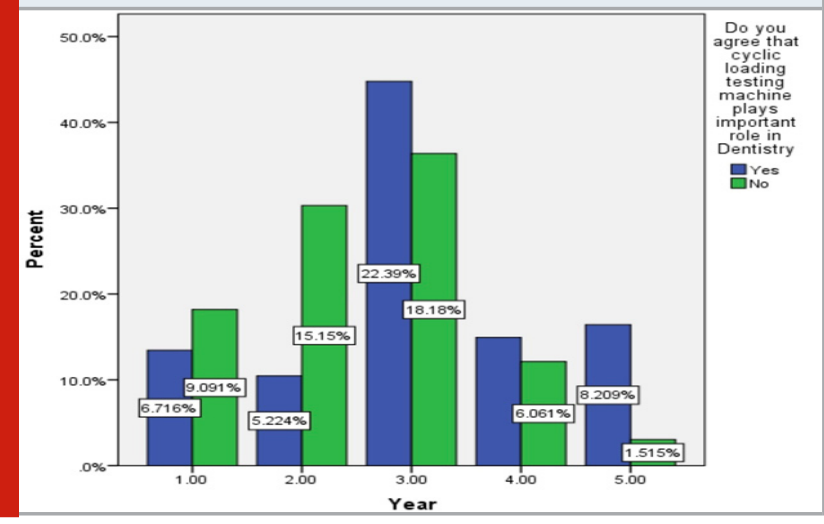

Figure 9: Bar graph shows the association between years of the study of the participants and awareness about cyclic loading testing machines. $\mathrm{X}$ axis represents the year of the study of participants and $\mathrm{Y}$ axis represents the percentage of undergraduate students who are aware of cyclic loading testing machine principles. Chi-square test was done and association was found to be statistically significant. Pearson's Chi-square value:25.951, DF:4, p value: $0.000(<0.05)$ hence statistically significant, proving that 3rd year (25.0\%), followed by Interns (13.16\%) and 4th year (9.211\%) undergraduate students have better awareness compared to 1 st and 2nd year of undergraduate students.

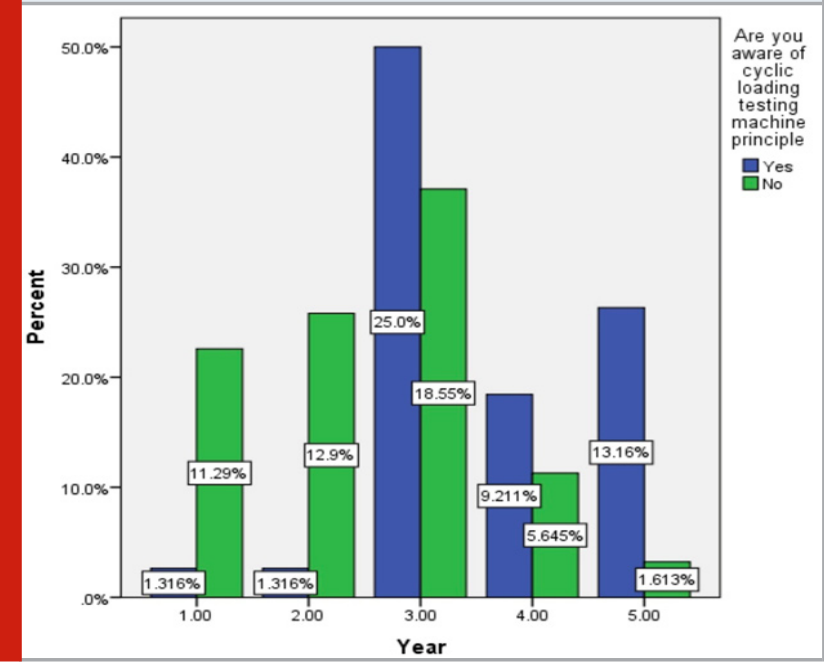


Figure 10: Bar graph shows the association between years of the study of the participants and awareness about cyclic loading testing machines. $\mathrm{X}$ axis represents the year of the study of participants and $\mathrm{Y}$ axis represents the percentage of undergraduate students who are aware that Servo- hydraulic testing machines are available in various sizes for testing both small and large loads. Chisquare test was done and association was found to be statistically significant. Pearson's Chi-square value:16.850, $\mathrm{DF}: 4$, p value: $0.002(<0.05)$ hence statistically significant, proving that 3rd year $(26.6 \%)$, followed by 4 th year (9.574\%) and Intern (7.447\%) undergraduate students have better awareness compared to 1 st and 2 nd year of undergraduate students.

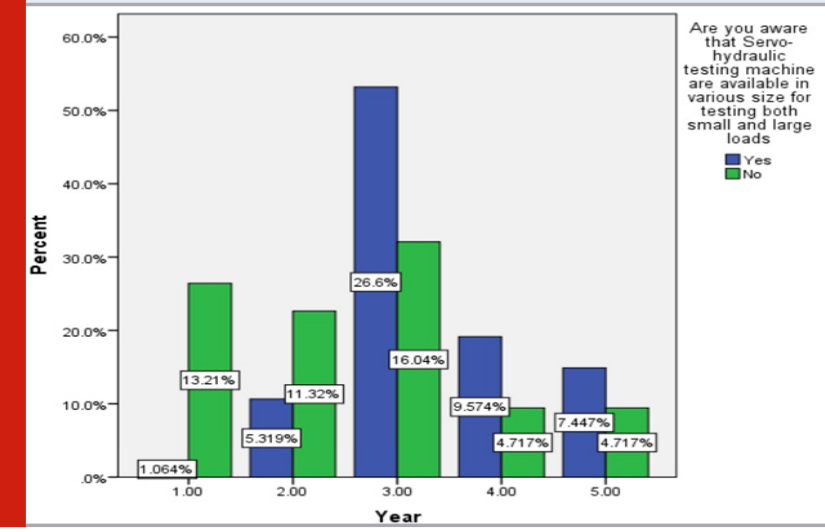

Limitations: There are certain limitations in our survey. There is a small sample size used for our survey which cannot be generated for a large population. And the survey doesn't represent the ethnic group and population.

Future Scope: The survey should be done in a larger population. Multicentered surveys should be done including other criterias.

\section{CONCLUSION}

Within the limitations of the study, we can concluded that 3rd year (25.0\%), 4th year (10.7\%), Intern (9.8\%) of them had higher awareness about cyclic loading testing machines than 1st year and 2nd year undergraduate dental students. Therefore for them group discussion and seminar can be conducted in order to create awareness on cyclic loading testing machines.

\section{ACKNOWLEDGEMENTS}

The author would like to acknowledge the help and support by the Department of Information Technology of Dental College and Hospital and the management for their constant assistance with the research

Conflict of Interest: Nil; Conflict of interest

\section{REFERENCES}

$\mathrm{Hu}$ Z. Work-hardening behavior of mild steel under cyclic deformation at finite strains. Acta Metallurgica et Materialia 1994;42:3481-91. https:// doi.org/10.1016/0956-7151(94)90480-4.

Li Q, Jin M, Zou Z, Zhao S, Zhang Q, Li P. Experiment Research on Tensile and Compression Cyclic Loading of Sheet Metal. Procedia Engineering 2017;207:1916-21. https://doi.org/10.1016/j.proeng.2017.10.961.

Studart AR, Filser F, Kocher P, Lüthy H, Gauckler LJ. Mechanical and fracture behavior of veneer-framework composites for all-ceramic dental bridges. Dental Materials 2007;23:115-23. https://doi.org/10.1016/j. dental.2005.12.009.

Zhang Y, Lawn B. Long-term strength of ceramics for biomedical applications. J Biomed Mater Res B Appl Biomater 2004;69:166-72.

Lohbauer U, Petschelt A, Greil P. Lifetime prediction of CAD/CAM dental ceramics. J Biomed Mater Res 2002;63:780-5.

Mitov G, Gessner J, Lohbauer U, Woll K, Muecklich F, Pospiech P. Subcritical crack growth behavior and life data analysis of two types of dental Y-TZP ceramics. Dent Mater 2011;27:684-91.

Studart AR, Filser F, Kocher P, Gauckler LJ. Fatigue of zirconia under cyclic loading in water and its implications for the design of dental bridges. Dental Materials 2007;23:106-14. https://doi.org/10.1016/j. dental.2005.12.008.

Scherrer SS, Denry IL, Anselm Wiskott HW. Comparison of three fracture toughness testing techniques using a dental glass and a dental ceramic. Dental Materials 1998;14:246-55. https://doi.org/10.1016/s01095641(98)00032-3.

Wang D, Xu YZ, Lu CL, Yang QX, Zhang DS, Shao LQ, et al. Comparison of Fracture Strength and Fracture Modes of Zirconia Dental Ceramics Manufactured by Four Different CAD/CAM Systems. Key Engineering Materials 2011;492:30-4. https://doi.org/10.4028/www. scientific.net/kem.492.30.

Jung Y-G, Peterson IM, Kim DK, Lawn BR. Lifetimelimiting Strength Degradation from Contact Fatigue in Dental Ceramics. Journal of Dental Research 2000;79:722-31. https://doi.org/10.1177/0022034500 0790020501.

Kohorst P, Dittmer MP, Borchers L, Stiesch-Scholz M. Influence of cyclic fatigue in water on the load-bearing capacity of dental bridges made of zirconia. Acta Biomaterialia 2008;4:1440-7. https://doi.org/10.1016/j. actbio.2008.04.012.

Lu C, Wang R, Mao S, Arola D, Zhang D. Reduction of load-bearing capacity of all-ceramic crowns due to cement aging. Journal of the Mechanical Behavior of Biomedical Materials 2013;17:56-65. https://doi. org/10.1016/j.jmbbm.2012.08.003.

Bresciano M, Schierano G, Manzella C, Screti A, 
Bignardi C, Preti G. Retention of luting agents on implant abutments of different height and taper. Clinical Oral Implants Research 2005;16:594-8. https://doi. org/10.1111/j.1600-0501.2005.01159.x.

Mansour A, Ercoli C, Graser G, Tallents R, Moss M. Comparative evaluation of casting retention using the ITI solid abutment with six cements. Clin Oral Implants Res 2002;13:343-8.

Dudley JE, Richards LC, Abbott JR. Retention of cast crown copings cemented to implant abutments. Australian Dental Journal 2008;53:332-9. https://doi. org/10.1111/j.1834-7819.2008.00075.x.

Bagde MN, Petroš V. Waveform Effect on Fatigue Properties of Intact Sandstone in Uniaxial Cyclical Loading. Rock Mechanics and Rock Engineering 2005;38:169-96. https://doi.org/10.1007/s00603-0050045-8.

Anbu RT, Suresh V, Gounder R, Kannan A. Comparison of the Efficacy of Three Different Bone Regeneration Materials: An Animal Study. Eur J Dent 2019;13:22-8.

Ashok V, Ganapathy D. A geometrical method to classify face forms. J Oral Biol Craniofac Res 2019;9:232-5.

Ganapathy DM, Kannan A, Venugopalan S. Effect of Coated Surfaces influencing Screw Loosening in Implants: A Systematic Review and Meta-analysis. World Journal of Dentistry 2017;8:496-502.

Jain AR. Clinical and Functional Outcomes of Implant Prostheses in Fibula Free Flaps. World Journal of Dentistry 2017;8:171-6.

Ariga P, Nallaswamy D, Jain AR, Ganapathy DM. Determination of Correlation of Width of Maxillary Anterior Teeth using Extraoral and Intraoral Factors in Indian Population: A Systematic Review. World Journal of Dentistry 2018;9:68-75.

Evaluation of Corrosive Behavior of Four Nickelchromium Alloys in Artificial Saliva by Cyclic Polarization Test:An in vitro Study. World Journal of Dentistry 2017;8:477-82.

Ranganathan H, Ganapathy DM, Jain AR. Cervical and Incisal Marginal Discrepancy in Ceramic Laminate Veneering Materials: A SEM Analysis. Contemp Clin Dent 2017;8:272-8.

Jain AR. Prevalence of Partial Edentulousness and Treatment needs in Rural Population of South India. World Journal of Dentistry 2017;8:213-7.

Duraisamy R, Krishnan CS, Ramasubramanian H, Sampathkumar J, Mariappan S, Navarasampatti Sivaprakasam A. Compatibility of Nonoriginal Abutments With Implants: Evaluation of Microgap at the Implant-Abutment Interface, With Original and Nonoriginal Abutments. Implant Dent 2019;28:28995.

Gupta P, Ariga P, Deogade SC. Effect of Monopolycoating Agent on the Surface Roughness of a Tissue Conditioner Subjected to Cleansing and Disinfection:
A Contact Profilometric Study. Contemp Clin Dent 2018;9:S122-6.

Varghese SS, Ramesh A, Veeraiyan DN. Blended Module-Based Teaching in Biostatistics and Research Methodology: A Retrospective Study with Postgraduate Dental Students. J Dent Educ 2019;83:445-50.

Patterson S, Ho YC, Wang WC. The Effect of Cyclic Loading on the Mechanical Performance of Surgical Mesh. EPJ Web of Conferences 2010;6:21007. https:// doi.org/10.1051/epjconf/20100621007.

Guo Y, Yang C, Wang L, Xu F. Effects of Cyclic Loading on the Mechanical Properties of Mature Bedding Shale. Advances in Civil Engineering 2018;2018:1-9. https:// doi.org/10.1155/2018/8985973.

McAlorum J, Rubert T, Fusiek G, Niewczas P, Zorzi G. Design and Demonstration of a Low-Cost Small-Scale Fatigue Testing Machine for Multi-Purpose Testing of Materials, Sensors and Structures. Machines 2018;6:30. https://doi.org/10.3390/machines6030030.

Liu E, He S. Effects of cyclic dynamic loading on the mechanical properties of intact rock samples under confining pressure conditions. Engineering Geology 2012;125:81-91. https://doi.org/10.1016/j. enggeo.2011.11.007.

Wang R-R, Lu C-L, Wang G, Zhang D-S. Influence of cyclic loading on the fracture toughness and load bearing capacities of all-ceramic crowns. International Journal of Oral Science 2014;6:99-104. https://doi. org/10.1038/ijos.2013.94.

Alvarez-Arenal A, Gonzalez-Gonzalez I, deLlanosLanchares H, Brizuela-Velasco A, Pinés-Hueso J, Ellakuria-Echebarria J. Retention Strength after Compressive Cyclic Loading of Five Luting Agents Used in Implant-Supported Prostheses. Biomed Res Int 2016;2016:2107027.

Hecker DM, Eckert SE. Cyclic loading of implantsupported prostheses: changes in component fit over time. J Prosthet Dent 2003;89:346-51.

Choi J-W, Kim S-Y, Bae J-H, Bae E-B, Huh J-B. In vitro study of the fracture resistance of monolithic lithium disilicate, monolithic zirconia, and lithium disilicate pressed on zirconia for three-unit fixed dental prostheses. The Journal of Advanced Prosthodontics 2017;9:244. https://doi.org/10.4047/jap.2017.9.4.244.

Mayer H. Recent developments in ultrasonic fatigue. Fatigue \&t Fracture of Engineering Materials \& Structures 2016;39:3-29. https://doi.org/10.1111/ffe.12365.

ieb KC, Horstman RT, Power B, Meltzer RL, Vieth MB, Charvat IMH, et al. The Development of a ClosedLoop, Servo-Hydraulic Test System for Direct Stress Monotonic and Cyclic Crack Propagation Studies Under Biaxial Loading. Journal of Testing and Evaluation 1980;8:9. https://doi.org/10.1520/jte10587j.

Lee Y-L. FATIGUE DAMAGE THEORIES. Fatigue Testing and Analysis 2005:57-76. https://doi.org/10.1016/b978075067719-6/50003-8. 